DR. EDUARDO VILAR-GOMEZ (Orcid ID : 0000-0003-1435-4013)

Article type : Original

Corresponding author mail id :- nchalasa@iu.edu

\title{
Vitamin E Improves Transplant-free Survival and Hepatic Decompensation among Patients with NASH and Advanced Fibrosis
}

Eduardo Vilar-Gomez ${ }^{1}$, Raj Vuppalanchi ${ }^{1}$, Samer Gawrieh ${ }^{1}$, Marwan Ghabril ${ }^{1}$, Romil Saxena $^{2}$, Oscar W Cummings ${ }^{2}$, Naga Chalasani ${ }^{1}$.

${ }^{1}$ Division of Gastroenterology and Hepatology, Indiana University School of Medicine, Indianapolis, IN, U.S.

${ }^{2}$ Department of Pathology, Indiana University School of Medicine, Indianapolis, IN, U.S.

\section{Corresponding author}

Naga Chalasani, MD

Indiana University School of Medicine

702 Rotary Circle

Suite 225

Indianapolis, IN 46202

Telephone 317-278-0414

Fax 317-278-1949

Key Words: Nonalcoholic steatohepatitis, bridging fibrosis, cirrhosis, vitamin E, survival, liver transplantation, hepatic decompensation, cardiovascular disease, hepatocellular carcinoma, and propensity score matching.

This is the author's manuscript of the article published in final edited form as:

Vilar-Gomez, E., Vuppalanchi, R., Gawrieh, S., Ghabril, M., Saxena, R., Cummings, O. W., \& Chalasani, N. (n.d.). Vitamin E Improves Transplant-free Survival and Hepatic Decompensation among Patients with NASH and Advanced Fibrosis. Hepatology, 0(ja). https://doi.org/10.1002/hep.30368 
Conflict of Interest: Authors declare no conflicts of interest relevant for this paper.

Financial support: There was no external funding for this study.

\begin{abstract}
Abbreviations:
NAFLD, nonalcoholic fatty liver disease; HCC, hepatocellular carcinoma; NASH, nonalcoholic steatohepatitis; RCT, randomized controlled trial; ICD, International classification of diseases; MELD, model for end-stage liver disease; CKD, chronic kidney disease; HIV, human immunodeficiency virus; INR, international normalized ratio; HDL, high density lipoprotein; LDL, low density lipoprotein; IU, international unit; CT, computed tomography; MRI, magnetic resonance imaging; US, ultrasound; BMI, body mass index; PS, propensity score; MICE, multiple imputations by chained equations; ALT, alanine aminotransferase; AST, aspartate aminotransferase; HR, hazard ratio; sHR, subhazard ratio; CVD, cardiovascular disease; NHANES, national health and nutrition examination survey; F, fibrosis; eGFR, estimated glomerular filtration rate; CI, confidence interval; CIs, cumulative incidences; IQR, interquartile range; RRR: relative risk reduction; ARR, absolute risk reduction; NNT, number needed to treat; T2D, type 2 diabetes.
\end{abstract}

\title{
ABSTRACT
}

Vitamin E improves liver histology in non-diabetic adults with nonalcoholic steatohepatitis (NASH), but its impact on long-term patient outcomes is unknown. We evaluated whether vitamin E treatment improves clinical outcomes of NASH patients with bridging fibrosis or cirrhosis. Two hundred and thirty-six patients with biopsy-proven NASH and bridging fibrosis or cirrhosis seen at Indiana University Medical Center between October 2004, and January 2016 were included. Ninety of them took $800 \mathrm{IU} /$ day of vitamin E for $\geq 2$ years (vitamin E users) and were propensity matched to 90 adults who did not take vitamin $\mathrm{E}$ (controls) after adjusting for fibrosis severity, age, gender, body mass index, comorbidities and their treatment, LDL cholesterol, liver biochemistries and length of follow-up on vitamin E. Covariate-adjusted cox and competing risk regression models were assessed to evaluate association between vitamin $\mathrm{E}$ treatment and patient outcomes. The median follow-up was 5.62 (IQR: 4.3-7.5) and 5.6 (IQR: 4-6.9) years for vitamin E users and controls respectively.

This article is protected by copyright. All rights reserved. 
Vitamin E users had higher adjusted transplant-free survival ( $78 \%$ vs. $49 \%, P<.01)$ and lower rates of hepatic decompensation ( $37 \%$ vs. $62 \%, P=.04)$ than controls. After controlling for severity of fibrosis, calendar year of patient enrollment and other potential confounders, vitamin E treatment decreased the risk of death or transplant (adj. HR: 0.30, 95\% CI: 0.12$0.74, P<.01$ ) and hepatic decompensation (adj. sHR: 0.52, 95\% CI: 0.28-0.96, $P=.036$ ). These benefits were evident in both diabetics as well as non-diabetics. Adjusted 10-year cumulative probability of $\mathrm{HCC}$, vascular events and non-hepatic cancers were not different between vitamin E exposed and controls. Conclusion, vitamin E use was associated with improved clinical outcomes in patients with NASH and bridging fibrosis or cirrhosis.

Nonalcoholic fatty liver disease (NAFLD) is a common cause of chronic liver disease and hepatocellular carcinoma (HCC), and recently has become a leading indication for liver transplantation in the industrialized countries.(1) The prevalence of NAFLD varies across the different countries, being from $20-30 \%$ in Europe and as high as $46 \%$ in the United States (U.S).(2, 3) The prevalence of NAFLD can also be higher in obese subjects and among patients with type 2 diabetes (T2D). Approximately 25\% patients with NAFLD may progress to nonalcoholic steatohepatitis (NASH), and $11 \%$ of NASH patients may developed cirrhosis within 15 years.(4) The prognosis of NAFLD is determined by the severity of hepatic fibrosis; patients with bridging fibrosis or cirrhosis carry a higher risk of hepatic decompensation secondary to portal hypertension, $\mathrm{HCC}$ and death as compared with patients with lower stages of fibrosis. $(5,6)$ Currently, there are no approved pharmacological interventions for NASH.(7) Lifestyle measures, including dietary changes and exercise have important benefits on NASH, however, significant body weight reduction $(>7 \%)$ is required to improve NASH and fibrosis, (8) which is difficult to achieve and harder to sustain over time.(8) Thus, there is an urgent need to develop safe and effective therapeutic options for patients with NASH, particularly targeting those with advanced liver fibrosis. Several drugs with different mechanism of actions and targets have been evaluated and/or are currently being tested for NASH, including vitamin E (9-12), pioglitazone (13) obeticholic acid (14), elafibranor (15), cenicriviroc (16), liraglutide (17) and selonsertib (18). Although most of them have shown clear beneficial effects on liver histology, including NASH resolution and fibrosis regression (surrogate markers of clinical outcomes), no efficacy data exist on longterm survival and clinical outcomes.

This article is protected by copyright. All rights reserved. 
Oxidative stress is suspected to play an important role in the progression to NASH and advanced fibrosis in NAFLD patients. Previous studies have confirmed a strong relationship between the severity of NAFLD and degree of oxidative stress.(19) Epidemiological studies have reported that low plasma levels of vitamin E are not only associated with presence of $\mathrm{NASH}(20)$ but also with increased all-cause mortality among NAFLD patients.(21) Vitamin E ( $\alpha$-tocopherol) is a well-known antioxidant that can protect cellular structure integrity against injury from lipid peroxidation and oxygen-free radicals. Several randomized controlled trials (RCT) have explored the efficacy of the supplementation of vitamin E $800 \mathrm{I} / \mathrm{U} /$ day on liver histology and aminotransferase levels of patients with NASH.(9-12) In two well-designed RCT conducted in adult and pediatric biopsy-proven NASH, vitamin E was associated with significant improvement in NASH histology, although there was no significant regression in liver fibrosis as compared with the placebo group. $(9,11)$ These results prompted the American Association for the Study of Liver Diseases (AASLD) to recommend vitamin E $800 \mathrm{I} / \mathrm{U} /$ day in nondiabetic and noncirrhotic patients with biopsy-confirmed NASH.(22) We conducted a study to investigate the impact of the vitamin $\mathrm{E}$ administration on long-term clinical outcomes in patients with biopsy-proven NASH and advanced fibrosis followed for up to 10 years in an academic tertiary referral center in the United States.

\section{MATERIALS AND METHODS}

\section{Study cohort}

This analysis consists of a retrospective study of all patients with biopsy-confirmed NASH and advanced fibrosis from October 2004 to January 2016 captured from the outpatient electronical medical record systems at Indiana University Medical Center, an academic tertiary referral center located in Indianapolis, Indiana. Patients were identified as having histologically-confirmed NASH with bridging fibrosis or cirrhosis according to an algorithm of International Classification of Diseases, Ninth and Tenth Revision (ICD-9/10) codes (571.8, K76.0, K75.81, 571.5, K76.0, K74.0, K74.60 and K74.69) along Current Procedural Terminology-4 codes $(50.1,50.11,50.12$, 50.13, 50.14, 0F903ZX, 0F904ZX, 0FB03ZX, 0F900Z, 0FB00ZX, 0FB03ZX, 0FB04ZX, 0FJ03ZZ, 47000, 47001, 47100, 75970, 75891, 75970, 75831, 76003). Subsequent individual chart reviews confirmed their clinical and histological diagnosis. All patients were seen by experienced hepatologists at the Indiana University Hospital following referral from community physicians. At our institution, the liver biopsies are generally performed in patients with suspected NAFLD for persistently

This article is protected by copyright. All rights reserved. 
increased ALT levels or high index of suspicion for NASH or advanced fibrosis. The decision to obtain a liver biopsy was part of standard clinical care and was made on a case by case basis by individual treating hepatologists.

For this study, eligible patients were $\geq 18$ years old with biopsy-confirmed NASH and bridging fibrosis or cirrhosis. The exclusion criteria were: history of decompensated cirrhosis (ascites, hepatic encephalopathy, variceal bleeding or a Child-Turcotte-Pugh score $\geq 7$ ) or presence of any event of hepatic decompensation prior to biopsy, MELD score $\geq 15$ (excluding values influenced by creatinine levels in the context of CKD), other causes of chronic liver diseases or secondary causes of NAFLD, known sero-positivity for HIV, type 1 diabetes, history of significant alcohol consumption ( $>20 \mathrm{~g} /$ day for men and $>10 \mathrm{~g} /$ day for women during the last two years), concomitant diseases with reduced life expectancy $(\leq 6$ months), platelet count $<40 \times 10^{9} \mathrm{~L}$, total serum bilirubin $>2.5 \mathrm{mg} / \mathrm{dl}$ and INR $>1.7$ and history of bariatric surgery before study entry or during follow-up. We only included patients with at least one year of follow-up after their study entry to ensure adequate exposure to vitamin $\mathrm{E}$ and also for assessing any safety signals. We also excluded patients who developed HCC or hepatic decompensation within the first 6 months of study enrollment in order to reduce potential lead time and length biases (Supplemental Table 1).

The institutional review board at Indiana University School of Medicine granted the study an exemption because the data were reviewed retrospectively, and analyses were deidentified.

\section{Patient data}

Baseline demographic, clinical, laboratory and concomitant medications data were collected at the time of liver biopsy for both vitamin E exposed and non-exposed patients after an extensive review of all medical and laboratory records. The extracted demographic and clinical data included age, gender, race, body weight in $\mathrm{kg}$, height, body mass index $\left(\mathrm{kg} / \mathrm{m}^{2}\right)$, history of comorbidities (type 2 diabetes, arterial hypertension, cardiovascular and cerebrovascular disease, chronic kidney disease, non-hepatic cancers) and its concurrent medications, self-reported alcohol consumption in the two years preceding the enrollment and tobacco use. Laboratory parameters, including aminotransferases, total bilirubin, serum albumin and creatinine, INR, platelets, fasting glucose and glycosylated hemoglobin, serum 
total and HDL cholesterol, triglyceride, LDL cholesterol, and alpha-fetoprotein were also recorded.

Histopathologic data were extracted by two trained hepatologist investigators from the original liver histology reports signed by 2 experienced hepatopathologists (OC, RS) who were primarily involved in scoring the liver biopsies which were obtained as part of standard clinical care. Only original reports were considered in our study. The NAFLD activity score (NAS) and their individual components (steatosis, 0-3; lobular inflammation, 0-3 and ballooning, 0-2) were calculated. The severity of fibrosis was staged from 0 to 4 , but only bridging fibrosis (stage 3 ) and cirrhosis (stage 4) were considered in the current analysis.(23, 24)

Data for vitamin E treatment was extracted from Medication Hub Service, which includes the medication issue date, dosage form, and days of supply for all medications dispensed by our affiliated pharmacies. Additionally, as vitamin E may be purchased overthe-counter outside our pharmacies, we captured such information through extensive review of each medical record. Vitamin E users were patients who consumed vitamin E (800 IU/day) for at least 2 years between October 2004 and January 2016. Non-vitamin E users (controls) were patients who did not receive a vitamin E treatment at any time throughout the study from October 2004, to January 2016. We identified all vitamin E prescriptions dispensed during follow-up to determine individuals' treatment status. For this study purposes, vitamin E users were defined as those who took vitamin $E$ for at least two years between the date of their first and last documented use. From our data extraction, we did not find any patients in the control group who received vitamin E prior to the liver biopsy or during their follow-up.

\section{Follow-up}

The follow-up period began on the date of biopsy for both controls and vitamin $\mathrm{E}$ users. After enrolled, all patients were systematically evaluated at $6-12$ intervals up to the study closure date (March 31, 2018), death, liver transplantation or lost to follow-up. Patients lost to follow-up were censored at the time of last known follow-up.

All patients underwent medical history along with physical examinations and laboratory tests at each follow-up visit. Follow-up data for outcomes were gathered from the ICD 9 and 10 codes and medical history, and confirmed through chart review of imaging, laboratory and/or 
pathological records based on the type of major event developed. All patients were regularly screened for HCC with cross-sectional abdominal imaging (liver ultrasound every 6 months, or CT or MRI every 9-12 months and alpha-fetoprotein every 6 months) and gastroesophageal varices according to the recommended guidelines. $(25,26)$ Treatment of liver and non-liver complications were provided according to our institutional standard of care and in general accordance with the practice guidelines.(25-28)

\section{Outcome measures}

All-cause mortality (including liver- and non-liver related) or liver transplantation was considered the primary outcome. Mortality ascribed to liver-related causes was defined as death with immediate cause from a complication of liver disease (i.e., variceal bleeding, hepatic encephalopathy or hepatorenal syndrome) or liver disease listed as a major contributing cause in medical chart review. Similarly, non-liver related causes were defined as those occurring as a direct complication of major vascular events (cardiovascular or cerebrovascular disease), cancers or other causes (i.e., sepsis).

Secondary outcomes were defined as follows: (1) hepatic decompensation: development of ascites (clinically- and/or US-detected), clinically overt hepatic encephalopathy and gastroesophageal variceal bleeding (verified by endoscopy); (2) vascular events- new episode of stroke (ischemic or hemorrhagic), myocardial infarction, stable or unstable angina, congestive heart failure, aneurysm dissection or cardiac arrest; (3) HCC, confirmed by imaging methods or liver biopsy; (4) non-hepatic malignancies other than HCC. Malignancies were defined as definite if a malignancy was reported on a biopsy or from an oncologist, radiation oncologist or hepatologist (specifically for HCC). Diagnoses of non-hepatic malignancies were verified using histopathology and/or cytology findings. Incident major vascular events were ascertained by self-report and documented by medical record review.

Each initial event was recorded when first seen during follow-up, and recurrence of the same event or occurrence of a new event belonging to the same category was not considered for the analyses. Likewise, outcomes occurring after liver transplantation were not accounted. All study outcomes were sequentially verified by two investigators by manual review of the medical records, including discharge summary and results of relevant 
diagnostic and laboratory tests. The second reviewer who verified the outcome events was blind to vitamin E exposure status during data extraction.

\section{Assembly of the propensity-matched cohort}

We used a 1:1 matching algorithm to match patients exposed and non-exposed to vitamin E.(29) A propensity-matched cohort was created using variables that were expected to increase the likelihood of receive vitamin $\mathrm{E}$ or increase the risk of overall mortality. To create the propensity-matched cohorts, we used logistic regression analysis, and the balance of covariates in our models was checked by Becker and Ichino strategies and then performed a nearest-number matching with a caliper of 0.01 using Leuven and Sianesi methodology.(30) The variables used to create the propensity score (PS) were: vitamin E as dependent variable and age, gender, tobacco use (current vs. former/nonsmoker), history of cardiovascular disease and malignancies, BMI, hypertension, type 2 diabetes, INR, total bilirubin, albumin, platelet count, LDL cholesterol, severity of fibrosis (bridging fibrosis or cirrhosis), use of antidiabetic medications, statins and aspirin, and length of follow-up after vitamin E firsttime prescription $(<4,4-6$ and $>6$ years $)$ as independent covariates or predictors. Further details are included in the supplemental material.

\section{Statistical analysis}

Quantitative variables were displayed as median and its interquartile ranges, and categorical as number and percentage. Wilcoxon rank-sum and Wilcoxon signed-rank tests for continuous covariates. Chi-square and McNemar's tests for binary variables. Standardized differences for categorical and continuous variables were also checked in the unmatched and matched cohorts.

Because vitamin E starting date was different among patients, vitamin E use was considered as a time-dependent covariate in order to avoid immortal-time bias.(31) Patients were coded as nonusers between liver biopsy and vitamin $\mathrm{E}$ initiation dates, and they were recoded to users on the date when vitamin E was initiated. In other words, for users, the code of the time-dependent covariate was 0 between the date of the liver biopsy and vitamin $\mathrm{E}$ prescription date and changed to 1 after vitamin E was started. Among patients who never used vitamin E, coding as nonuser was applied throughout. This method is more accurate for defining vitamin E exposure status since classifies the person-time of the users before their first prescription as the unexposed follow-up time. Time-dependent cox and competing risk 
regression models were computed to calculate unadjusted and adjusted hazard and subhazard ratios with $95 \%$ confidence intervals $(\mathrm{CI})$.

Given that outcomes probabilities may be influenced by the severity of fibrosis (bridging fibrosis vs. cirrhosis) and calendar year of patient recruitment, the cumulative probabilities for transplant-free survival and major clinical events were always adjusted for these two variables. For adjusted curves, time-dependent cox regression-based tests were implemented to compare difference between transplant-free survival distributions, whereas time-dependent competing risk regression-based tests were used to compare difference between major clinical outcomes sub-distributions.

The primary analysis was based on PS-matched groups. Additional sensitivity analyses were undertaken to corroborate the findings from our PS analyses in the unmatched cohort. Thus, we estimated differences in outcomes based on vitamin E use in both the PSmatched as well as the unmatched cohorts. Time-dependent cox regression models were used to assess association of vitamin $\mathrm{E}$ with transplant-free survival, whereas time-dependent competing risk regression models were implemented based on the method of Fine and Gray to evaluate association of vitamin $\mathrm{E}$ with major clinical outcomes (hepatic decompensation, HCC, vascular events and nonhepatic cancers) (see supplemental material for more details). To provide an optimal control for risk factors and confounders, three covariateadjusted analyses were performed, including vitamin $\mathrm{E}$ use as a time varying covariate, as described previously. Adjusted analyses were conducted including the following potential risk factors or confounders: age, gender, tobacco use, history of cardiovascular or cerebrovascular disease, LDL cholesterol, BMI, hypertension, type 2 diabetes, fibrosis severity, presence of esophageal varices at baseline, calendar year of patient enrollment and use of antidiabetic medications, statins and aspirin (model 1) or adding MELD score (model 2) or liver function tests (total bilirubin, INR, albumin and platelet count) (model 3) to the same variables included in the model 1. Covariates were selected for the adjusted analyses based on their biologically plausible potential to act as confounders, well-known predictors of outcomes and variables that were significant $(\mathrm{P}<0.15)$ in the univariate analyses. Presence of cirrhosis, MELD score and specific liver function tests were highly predictive of mortality and hepatic decompensation, thereby, multivariable models were adjusted by these covariates (Supplemental Table 2).

This article is protected by copyright. All rights reserved. 
Covariates with missing values were imputed to avoid case deletion in our PS and multivariable analyses. We did not find covariates with more than $10 \%$ of missing values. We applied a method of multiple imputations by chained equation (MICE) in which missing data are imputed or replaced with a set of plausible values using regression-based models. We did 20 imputations for each missing information. A log-log survival curves and Schoenfeld residuals were used to check proportional hazard assumptions. The assumptions of proportionality were met both globally (the overall models) and individually for each predictor covariate.

All testing was 2 -sided, and $P \leq 0.05$ was considered as statistically significant. All analyses were conducted using Stata (version 15.0, Stata Cop, College Station, Texas, USA).

\section{RESULTS}

\section{Study Cohort}

A total of 307 patients with biopsy-proven NASH with bridging fibrosis and compensated cirrhosis were identified during the study period, but 71 not meet our eligibility criteria were excluded from the study. Thus, a total of 236 individuals with NASH and bridging fibrosis or compensated cirrhosis constituted our study cohort (Figure 1). Of them, 90 were vitamin E users whereas 146 individuals did not receive vitamin E during the study period. The median follow-up was 6.5 (IQR: 4.6.8) years in unmatched controls. The selected clinical characteristics of vitamin E users and vitamin E non-users in this cohort of 236 patients are shown in Supplemental Table 3.

Propensity scoring (PS) matching resulted in well-balanced cohorts of patients on vitamin $E(n=90)$ and non-exposed controls $(n=90)$, which were comparable in all baseline features except for ALT, AST and LDL cholesterol median levels (Table 1). Patients were predominantly cirrhotic on biopsy (68\% vitamin E users and $73 \%$ controls) and the majority had active necroinflammation on their biopsy (NAFLD Activity Score $\geq 4$ in $68 \%$ in vitamin E users and 57\% in controls). Since liver biopsy date, the median follow-up was 7.1 (5.4-9.5) years among vitamin E users and 5.62 (IQR, 4.3-7.5) years in controls. From vitamin E prescription date, the median follow-up was 5.6 (IQR, 4-6.9). Table 1 summarizes other selected baseline characteristics of vitamin E users and their PS matched controls.

This article is protected by copyright. All rights reserved. 


\section{Association between vitamin $\mathbf{E}$ use and study outcomes}

\section{(a) All-cause mortality or transplant and hepatic decompensation rates}

The overall mortality and transplant rates were significantly lower among vitamin $\mathrm{E}$ users $(10 \%)$ than their PS matched controls $(33 \%, P<.001)$ (Table 2). Ten-year timedependent cox-model adjusted transplant-free survival rate was significantly higher among vitamin E users (78\%) than their matched controls $(49 \%, P<.01)$ (Figure 2A). In timedependent covariate-adjusted cox regression models, vitamin E use remained a significant protector against overall mortality or transplant after controlling by fibrosis severity (HR: 0.30, 95\% CI: 0.12-0.74, $P<.01$ ), MELD score (HR: 0.34, 95\% CI: 0.14-0.85, $P=.02$ ) and liver function tests (HR: 0.41, 95\% CI: 0.18-0.94, $P=.036$ ) (Table 3). Vitamin E exposed patients showed a significant reduction of relative (70\%, 95\% CI: 40-85) and absolute (23\%, $95 \%$ CI: 12-35) risks of overall mortality or transplant, yielding a number needed to treat (NNT) of 4.28 (95\% CI: 8.48-2.87). Most of vitamin E beneficial effects were observed on liver-related mortality or transplant (absolute risk reduction, 16\%), Supplemental Table 4. The proportion of patients who developed an initial event of hepatic decompensation during follow-up was significantly lower in the vitamin E group than controls (37\% vs. $62 \%$, $P=.044$ ), while adjusting by fibrosis severity and calendar year of patient enrollment (Figure 2B). Vitamin E treated patients had reduced risk of hepatic decompensation than controls after competing risk adjusted analysis by fibrosis severity (sHR: 0.52, 95\% CI: 0.28-0.96, P.036), MELD score (sHR: 0.53, 95\% CI: 0.29-0.98, $P=.042$ ) and liver function tests (sHR: $0.55,95 \%$ CI: $0.30-0.98, P=.048)$ (Table 3).

In the entire study cohort consisting of 90 vitamin E user and 146 unmatched vitamin E non-users, vitamin E use was significantly associated with lower overall mortality or transplantation, even after adjusting for fibrosis severity, MELD score, liver function tests, and other baseline co-variates (Supplemental Table 5 and 6 and Supplemental Figure 1A). Similarly, vitamin E use was associated with significantly lower frequency of an initial event of hepatic decompensation as well as significantly lower cumulative incidence of hepatic decompensation, even in the competing risk analyses after adjusting for fibrosis severity, MELD score, liver function tests, and other baseline co-variates (Supplemental Table 5 and 6 and Supplemental Figure 1B).

This article is protected by copyright. All rights reserved. 


\section{(b) Development of HCC, major vascular events and non-hepatic cancers}

After competing risk model adjustments by severity of fibrosis and calendar year of patient recruitment, 10-year cumulative incidences of HCC (vitamin E users: 19\% vs. matched controls: $20 \%$, adj. $P=.95$ ), major vascular events (vitamin E users: $14 \%$ vs. matched controls: $17 \%$, adj. $P=.70$ ) and non-hepatic cancers (vitamin E users: $8 \%$ vs. matched controls: $6 \%$, adj. $P=.74$ ) were not different between the vitamin $E$ users and their matched controls (Figures 2A-C). Likewise, in the entire study cohort consisting of 90 vitamin E user and 146 unmatched vitamin E non-users, the 10-year cumulative rates of HCC, major vascular events and non-hepatic cancers were similar between vitamin E users and their unmatched controls (Supplemental Figures 2A-C).

\section{(c) Benefits of vitamin $E$ use and type 2 diabetes in the propensity score adjusted analyses}

The significant beneficial effects of vitamin E treatment were evident among patients with or without type 2 diabetes. The risk of all-cause mortality or transplant was significantly reduced in nondiabetic (adj. HR: 0.19, 95\% CI: 0.05-0.74, $P=.01$ ) and diabetic (adj. HR: 0.29, $95 \% \mathrm{CI}: 0.11-0.76, P=.01)$ patients after adjustments by fibrosis severity and calendar year of patient recruitment (Figure 4). Similar observation was made in the unmatched cohort where vitamin $\mathrm{E}$ use was independently associated with lower overall mortality or transplant in diabetics (adj. HR: 0.51, 95\% CI: 0.22-0.97, $P=.048$ ) as well as in nondiabetics (adj. HR: 0.29, 95\% CI: 0.08-0.89, $P=.041)$, Supplemental Figure 3.

\section{(d) Change from baseline in selected laboratory tests in PS-matched groups}

Table 4 summarizes change from baseline in selected baseline characteristics.

Vitamin E users showed a marked reduction from the baseline in their mean ALT (-30.7 vs. $11 \mathrm{U} / \mathrm{L}$ ) and AST (-22.9 vs. $-7.5 \mathrm{U} / \mathrm{L}$ ) levels as compared with nonusers (all $P<.01$ ). Among unexposed patients, there was significant worsening from baseline of mean INR (0.31 vs. $0.14)$, total bilirubin (0.71 vs. $0.42 \mathrm{mg} / \mathrm{dl})$, albumin $(-0.42$ vs. $-0.18 \mathrm{mg} / \mathrm{dl})$ and Fib-4 (1.48 vs. 1.12) levels as compared with vitamin E exposed patients (all $P<.05$ ).

\section{DISCUSSION}

In the current study, long-term vitamin E use was associated with lower rates of allcause mortality or liver transplantation and development of hepatic decompensation in unmatched and propensity-matched analyses after adjusting for potential confounders. Long- 
term treatment with vitamin $\mathrm{E}$ was associated with $70 \%$ risk reduction of all-cause mortality or transplant, and the risk was particularly reduced for liver-related mortality or transplant (68\%), yielding NNT of 4.18 and 6.16, respectively. Likewise, a 35\% reduction in relative risk of hepatic decompensation rates was observed in vitamin E exposed groups compared with the control group, yielding a NNT of 6.43 (Supplemental Table 4). Despite of benefits on survival and hepatic decompensation, vitamin $\mathrm{E}$ was not associated with a reduced risk of HCC. Our data also suggest that benefits of taking vitamin E can be extended to diabetic patients with biopsy-proven NASH and advanced fibrosis. The risk of death or transplant was markedly reduced up to $71 \%$ and $81 \%$ in diabetic and nondiabetic vitamin $\mathrm{E}$ users as compared with nonusers, even after controlling by severity of fibrosis and calendar year of patient recruitment.

The risk of non-liver related outcomes, including development of cardiovascular or cerebrovascular disease and non-hepatic cancers was not higher in vitamin $\mathrm{E}$ users versus nonusers, although the number of such events was significantly lower as compared with the development of decompensation secondary to portal hypertension. Concerns have been raised about long-term safety of vitamin E exposure, particularly in high doses. It has been suggested that long-term exposure to vitamin E especially at doses $\geq 400 \mathrm{IU} / \mathrm{d}$ is associated with slightly increased risks of overall mortality (32), incidence of hemorrhagic stroke (33) and prostate cancer (34). However, the meta-analyses combining RCT designed to evaluate the vitamin E efficacy for prevention or treatment of CVD, did not find evidence that vitamin $\mathrm{E}$ in daily doses up to $800 \mathrm{I} / \mathrm{U}$ either increased or decreased all-cause or cardiovascularspecific mortality.(35) It is comforting that in our study we did not observe a safety signal for vitamin $\mathrm{E}$ use, but our sample size is vastly underpowered for detecting very rare safety signals.

The effects of vitamin E has been extensively investigated in experimental models of NAFLD. In mice fed with methionine-choline-deficient diet, vitamin E supplementation reduced steatosis, necroinflammation and fibrosis as compared with mice controls, and these effects were associated with significant reduction in malondialdehyde, increase in superoxide dismutase activity and hepatic glutathione repletion, reduction in hepatic stellate cell activation, and downregulation of genes expression related to inflammation and fibrosis, such as TNF- $\alpha$ and TGF- $\beta 1 .(36,37)$ Beyond of antioxidant effects, vitamin $E$ has also been implicated in the regulation of inflammatory response via several enzymes involved in signal 
transduction as well as expression of specific genes closely related to inflammatory pathways, cellular trafficking and proliferation. $(38,39)$ The inhibition of protein kinase $\mathrm{C}$ by $\alpha$-tocopherol has been associated with reduced proliferation of vascular smooth cells, macrophages and fibroblast as well as decreased secretion of endothelin by endothelial cells.(40, 41) Vitamin $\mathrm{E}$ is also able to downregulate genes expressions encoding for proteins with active participation in inflammatory response pathways (E-selectin, VCAM-1, integrin, IL-1b, transforming growth factor) and extracellular matrix formation and degradation (MMP-1 and MMP-19).(39) The above-mentioned favorable effects of vitamin E on inflammation, fibrosis and endothelial dysfunction may potentially explain the improvement in survival or hepatic decompensation rates seen in the current study.

Our study showed that vitamin E supplementation had no effect on the primary prevention of HCC development, although the number of events (only $13 \mathrm{HCC}$ ) observed in our study was low. Although experimental and epidemiological studies have shown preventive effect of antioxidant supplements on cancer,(42) previous randomized controlled trials and meta-analyses have not consistently shown cancer prevention by antioxidants.(43)

Our study has several important limitations. First of all, its retrospective and nonrandomized design is invariably less rigorous than a double blind randomized controlled trial. By propensity matching and controlling extensively for potential confounders, we attempted to minimize imbalance between two groups, but it is possible that there are unrecognized confounders responsible for the results we observed in this analysis. Second, in a nonrandomized study, an important question comes up to why some patients received vitamin $\mathrm{E}$ while others did not. Although there is no evidence to support treating patients with NASH cirrhosis or diabetics with NASH and bridging fibrosis, three busy hepatologists (out of more than 10) who practiced at our institution during the study period routinely offered vitamin $\mathrm{E}$ to a broad spectrum of NAFLD patients very soon after initial reports supporting vitamin $\mathrm{E}$ use have appeared in the literature. Third, as our cohort consisted of predominantly cirrhotics, our results may not generalize to populations with bridging fibrosis. It is possible that vitamin E treatment reduces mortality and hepatic outcomes for cirrhotic patients and not for bridging fibrosis, but we did not have sufficient sample size to examine whether the association varied across subgroups. Fourth, using pharmacy data to identify vitamin use is another limitation because it captures prescriptions and not necessarily consumption. However, most vitamin $\mathrm{E}$ users received prescriptions for prolonged periods, which may suggest actual compliance

This article is protected by copyright. All rights reserved. 
with such prescriptions. We additionally ascertained vitamin E intake by reviewing the list of current medications at each visit. Since vitamin E can be also obtained over-the-counter, vitamin E exposure in the controls cannot be completely excluded. Fourth, as aforementioned, our sample size is too small to detect rare adverse effects which previously have been attributed to long-term use of vitamin E. Fifth, as our cohort is entirely comprised of Caucasians, our results may not be generalizable to other racial and ethnic groups. Finally, vitamin E treatment effects on study outcomes represent an association and not necessarily a causal effect between vitamin E exposure and survival or hepatic decompensation. Therefore, further RCT are necessary to confirm vitamin E treatment effects in patients with NASH and advanced fibrosis. Our data should provide important insights for designing goals and planning an adequate sample size for a future RCT. Despite these important limitations, our study is an important contribution to the literature because of critical dearth of data evaluating the utility of vitamin $\mathrm{E}$ or any other intervention in improving clinical outcomes of patients with NAFLD.

In conclusion, in this non-randomized propensity-score adjusted study we observed that $800 \mathrm{IU} / \mathrm{day}$ vitamin E was associated with significant reduction in overall mortality and hepatic decompensation in both diabetics and non-diabetics patients with bridging fibrosis and cirrhosis due to NASH. Although it is reassuring that we did not observe any safety signals associated with long term high dose vitamin $\mathrm{E}$ use, our study is very underpowered for detecting rare adverse events. These data urgently call for a randomized, double-blind, placebo-controlled trial to confirm these preliminary and yet very promising results.

\section{REFERENCES}

1. Younossi ZM, Koenig AB, Abdelatif D, Fazel Y, Henry L, Wymer M. Global epidemiology of nonalcoholic fatty liver disease-Meta-analytic assessment of prevalence, incidence, and outcomes. Hepatology 2016;64:73-84.

2. Armstrong MJ, Houlihan DD, Bentham L, Shaw JC, Cramb R, Olliff S, Gill PS, et al. Presence and severity of non-alcoholic fatty liver disease in a large prospective primary care cohort. J Hepatol 2012;56:234-240. 
3. Williams CD, Stengel J, Asike MI, Torres DM, Shaw J, Contreras M, Landt CL, et al. Prevalence of Nonalcoholic Fatty Liver Disease and Nonalcoholic Steatohepatitis Among a Largely Middle-Aged Population Utilizing Ultrasound and Liver Biopsy: A Prospective Study. Gastroenterology 2011;140:124-131.

4. Torres DM, Williams CD, HarrisonO SA. Features, Diagnosis, and Treatment of Nonalcoholic Fatty Liver Disease. Clinical Gastroenterology and Hepatology 2012;10:837858.

5. Angulo P, Kleiner DE, Dam-Larsen S, Adams LA, Bjornsson ES, Charatcharoenwitthaya P, Mills PR, et al. Liver Fibrosis, but No Other Histologic Features, Is Associated With Long-term Outcomes of Patients With Nonalcoholic Fatty Liver Disease. Gastroenterology 2015;149:389-397.

6. Vilar-Gomez E, Calzadilla-Bertot L, Wai-Sun Wong V, Castellanos M, Aller-de la Fuente R, Metwally M, Eslam M, et al. Fibrosis Severity as a Determinant of Cause-Specific Mortality in Patients With Advanced Nonalcoholic Fatty Liver Disease: A Multi-National Cohort Study. Gastroenterology 2018;155:443-457 e417.

7. Chalasani N, Younossi Z, Lavine JE, Charlton M, Cusi K, Rinella M, Harrison SA, et al. The diagnosis and management of nonalcoholic fatty liver disease: Practice guidance from the American Association for the Study of Liver Diseases. Hepatology 2018;67:328-357. 8. Vilar-Gomez E, Martinez-Perez Y, Calzadilla-Bertot L, Torres-Gonzalez A, GraOramas B, Gonzalez-Fabian L, Friedman SL, et al. Weight Loss Through Lifestyle Modification Significantly Reduces Features of Nonalcoholic Steatohepatitis. Gastroenterology 2015;149:367-378.

9. Sanyal AJ, Chalasani N, Kowdley KV, McCullough A, Diehl AM, Bass NM, Neuschwander-Tetri BA, et al. Pioglitazone, vitamin E, or placebo for nonalcoholic steatohepatitis. N Engl J Med 2010;362:1675-1685.

10. Harrison SA, Torgerson S, Hayashi P, Ward J, Schenker S. Vitamin E and vitamin C treatment improves fibrosis in patients with nonalcoholic steatohepatitis. American Journal of Gastroenterology 2003;98:2485-2490.

11. Lavine JE, Schwimmer JB, Van Natta ML, Molleston JP, Murray KF, Rosenthal P, Abrams SH, et al. Effect of vitamin E or metformin for treatment of nonalcoholic fatty liver disease in children and adolescents: the TONIC randomized controlled trial. JAMA 2011;305:1659-1668.

This article is protected by copyright. All rights reserved. 
12. Dufour JF, Oneta CM, Gonvers JJ, Bihl F, Cerny A, Cereda JM, Zala JF, et al. Randomized placebo-controlled trial of ursodeoxycholic acid with vitamin $\mathrm{E}$ in nonalcoholic steatohepatitis. Clinical Gastroenterology and Hepatology 2006;4:1537-1543.

13. Cusi K, Orsak B, Bril F, Lomonaco R, Hecht J, Ortiz-Lopez C, Tio F, et al. LongTerm Pioglitazone Treatment for Patients With Nonalcoholic Steatohepatitis and Prediabetes or Type 2 Diabetes Mellitus: A Randomized Trial. Ann Intern Med 2016;165:305-315.

14. Neuschwander-Tetri BA, Loomba R, Sanyal AJ, Lavine JE, Van Natta ML, Abdelmalek MF, Chalasani N, et al. Farnesoid X nuclear receptor ligand obeticholic acid for non-cirrhotic, non-alcoholic steatohepatitis (FLINT): a multicentre, randomised, placebocontrolled trial. Lancet 2015;385:956-965.

15. Ratziu V, Harrison SA, Francque S, Bedossa P, Lehert P, Serfaty L, Romero-Gomez M, et al. Elafibranor, an Agonist of the Peroxisome Proliferator-Activated Receptor-alpha and -delta, Induces Resolution of Nonalcoholic Steatohepatitis Without Fibrosis Worsening. Gastroenterology 2016;150:1147-1159 e1145.

16. Friedman SL, Ratziu V, Harrison SA, Abdelmalek MF, Aithal GP, Caballeria J, Francque $\mathrm{S}$, et al. A randomized, placebo-controlled trial of cenicriviroc for treatment of nonalcoholic steatohepatitis with fibrosis. Hepatology 2018;67:1754-1767.

17. Armstrong MJ, Gaunt P, Aithal GP, Barton D, Hull D, Parker R, Hazlehurst JM, et al. Liraglutide safety and efficacy in patients with non-alcoholic steatohepatitis (LEAN): a multicentre, double-blind, randomised, placebo-controlled phase 2 study. Lancet 2016;387:679-690.

18. Loomba R, Lawitz E, Mantry PS, Jayakumar S, Caldwell SH, Arnold H, Diehl AM, et al. The ASK1 inhibitor selonsertib in patients with nonalcoholic steatohepatitis: A randomized, phase 2 trial. Hepatology 2018;67:549-559.

19. Hardwick RN, Fisher CD, Canet MJ, Lake AD, Cherrington NJ. Diversity in antioxidant response enzymes in progressive stages of human nonalcoholic fatty liver disease. Drug Metab Dispos 2010;38:2293-2301.

20. Erhardt A, Stahl W, Sies H, Lirussi F, Donner A, Haussinger D. Plasma levels of vitamin $\mathrm{E}$ and carotenoids are decreased in patients with Nonalcoholic Steatohepatitis (NASH). Eur J Med Res 2011;16:76-78.

21. Daniel K, Tekeste T, Ditah IC. Low Vitamin E Levels in Nafld Patients Are Associated with Increased All Cause Mortality: A 23-Year Prospective Population-Based Study. Gastroenterology 2017;152:S1201-S1201. 
22. Chalasani N, Younossi Z, Lavine JE, Diehl AM, Brunt EM, Cusi K, Charlton M, et al. The Diagnosis and Management of Non-alcoholic Fatty Liver Disease: Practice Guideline by the American Gastroenterological Association, American Association for the Study of Liver Diseases, and American College of Gastroenterology. Gastroenterology 2012;142:1592-1609. 23. Kleiner DE, Brunt EM, Van Natta M, Behling C, Contos MJ, Cummings OW, Ferrell LD, et al. Design and validation of a histological scoring system for nonalcoholic fatty liver disease. Hepatology 2005;41:1313-1321.

24. Brunt EM, Kleiner DE, Wilson LA, Belt P, Neuschwander-Tetri BA, Network NCR. Nonalcoholic fatty liver disease (NAFLD) activity score and the histopathologic diagnosis in NAFLD: distinct clinicopathologic meanings. Hepatology 2011;53:810-820.

25. Bruix J, Sherman M, American Association for the Study of Liver D. Management of hepatocellular carcinoma: an update. Hepatology 2011;53:1020-1022.

26. Garcia-Tsao G, Sanyal AJ, Grace ND, Carey W, Practice Guidelines Committee of the American Association for the Study of Liver D, Practice Parameters Committee of the American College of G. Prevention and management of gastroesophageal varices and variceal hemorrhage in cirrhosis. Hepatology 2007;46:922-938.

27. Runyon BA, Committee APG. Management of adult patients with ascites due to cirrhosis: an update. Hepatology 2009;49:2087-2107.

28. American Association for the Study of Liver D, European Association for the Study of the L. Hepatic encephalopathy in chronic liver disease: 2014 practice guideline by the European Association for the Study of the Liver and the American Association for the Study of Liver Diseases. J Hepatol 2014;61:642-659.

29. Austin PC. Statistical criteria for selecting the optimal number of untreated subjects matched to each treated subject when using many-to-one matching on the propensity score. Am J Epidemiol 2010;172:1092-1097.

30. Garrido MM, Kelley AS, Paris J, Roza K, Meier DE, Morrison RS, Aldridge MD. Methods for constructing and assessing propensity scores. Health Serv Res 2014;49:17011720 .

31. Zhou Z, Rahme E, Abrahamowicz M, Pilote L. Survival bias associated with time-totreatment initiation in drug effectiveness evaluation: a comparison of methods. Am J Epidemiol 2005;162:1016-1023.

32. Miller ER, Pastor-Barriuso R, Dalal D, Riemersma RA, Appel LJ, Guallar E. Metaanalysis: High-dosage vitamin E supplementation may increase all-cause mortality. Annals of Internal Medicine 2005;142:37-46.

This article is protected by copyright. All rights reserved. 
33. Schurks M, Glynn RJ, Rist PM, Tzourio C, Kurth T. Effects of vitamin E on stroke subtypes: meta-analysis of randomised controlled trials. BMJ 2010;341:c5702.

34. Klein EA, Thompson IM, Tangen CM, Crowley JJ, Lucia MS, Goodman PJ, Minasian LM, et al. Vitamin E and the Risk of Prostate Cancer The Selenium and Vitamin E Cancer Prevention Trial (SELECT). Jama-Journal of the American Medical Association 2011;306:1549-1556.

35. Vivekananthan DP, Penn MS, Sapp SK, Hsu A, Topol EJ. Use of antioxidant vitamins for the prevention of cardiovascular disease: meta-analysis of randomised trials. Lancet 2003;361:2017-2023.

36. Nan YM, Wu WJ, Fu N, Liang BL, Wang RQ, Li LX, Zhao SX, et al. Antioxidants vitamin $\mathrm{E}$ and 1-aminobenzotriazole prevent experimental non-alcoholic steatohepatitis in mice. Scand J Gastroenterol 2009;44:1121-1131.

37. Phung N, Pera N, Farrell G, Leclercq I, Hou JY, George J. Pro-oxidant-mediated hepatic fibrosis and effects of antioxidant intervention in murine dietary steatohepatitis. Int $\mathbf{J}$ Mol Med 2009;24:171-180.

38. Boscoboinik D, Szewczyk A, Hensey C, Azzi A. Inhibition of cell proliferation by alpha-tocopherol. Role of protein kinase C. J Biol Chem 1991;266:6188-6194.

39. Rimbach G, Moehring J, Huebbe P, Lodge JK. Gene-regulatory activity of alphatocopherol. Molecules 2010;15:1746-1761.

40. Cook-Mills JM. Isoforms of Vitamin E Differentially Regulate PKC alpha and Inflammation: A Review. J Clin Cell Immunol 2013;4.

41. Martin-Nizard F, Boullier A, Fruchart JC, Duriez P. Alpha-tocopherol but not betatocopherol inhibits thrombin-induced PKC activation and endothelin secretion in endothelial cells. J Cardiovasc Risk 1998;5:339-345.

42. Hercberg S, Galan P, Preziosi P, Alfarez MJ, Vazquez C. The potential role of antioxidant vitamins in preventing cardiovascular diseases and cancers. Nutrition 1998;14:513-520.

43. Myung SK, Kim Y, Ju W, Choi HJ, Bae WK. Effects of antioxidant supplements on cancer prevention: meta-analysis of randomized controlled trials. Ann Oncol 2010;21:166179.

This article is protected by copyright. All rights reserved. 


\section{FIGURE LEGENDS}

Fig. 1. Flow chart of patients through the study cohort.

* Median follow-up after vitamin E was initiated.

Fig. 2. Adjusted* cumulative probability of transplant-free survival or hepatic decompensation in PS-matched cohort.

(A) Time-dependent cox model estimated cumulative probability of transplant-free survival.

(B) Time-dependent competing risk estimated cumulative incidence of the first event of hepatic decompensation.

*Adjustments by fibrosis severity (bridging fibrosis or cirrhosis) and calendar year of patient enrollment.

Abbreviations: CIs, cumulative incidences.

Fig. 3. Adjusted* cumulative incidence of other major outcomes in PS-matched cohort. Analysis based on time-dependent competing risk models.

(A) Hepatocellular carcinoma.

(B) Major vascular events.

(C) Non-hepatic cancers.

*Adjustments by fibrosis severity (bridging fibrosis or cirrhosis) and calendar year of patient enrollment.

Abbreviations: CIs, cumulative incidences.

Fig. 4. Adjusted* cumulative probability of transplant-free survival among patients with $(n=121)$ or without $(n=59)$ type 2 diabetes. Analysis based on time-dependent cox regression models.

*Adjustments by fibrosis severity (bridging fibrosis or cirrhosis) and calendar year of patient enrollment.

Abbreviations: T2D, type 2 diabetes.

Adj. HR of all-cause mortality or transplant for vitamin E in diabetic cohort: 0.29 (95\% CI:

$0.11-0.76), \mathrm{P}=.01$

Adj. HR of all-cause mortality or transplant for vitamin E in nondiabetic cohort: $0.19(95 \%$

CI: $0.05-0.74), \mathrm{P}=.01$

This article is protected by copyright. All rights reserved. 


\section{TABLES}

Table 1. Selected Baseline characteristics of vitamin E users and their propensity-matched controls

\begin{tabular}{|c|c|c|c|c|}
\hline \multirow[b]{2}{*}{ Variables } & \multicolumn{4}{|c|}{ Propensity-matched cohort, $\mathrm{N}=180$} \\
\hline & $\begin{array}{l}\text { Controls } \\
\mathrm{n}=90\end{array}$ & $\begin{array}{l}\text { Vitamin E } \\
\mathrm{n}=90\end{array}$ & $\mathrm{P}^{*}$ & $\begin{array}{l}\text { Standardized } \\
\text { differencet }\end{array}$ \\
\hline Median follow-up (years) & $5.62(4.3-7.5)$ & $5.60(4-6.9)$ & .22 & 0.102 \\
\hline \multicolumn{5}{|l|}{ Demographics } \\
\hline Age & $56(49.9-61.7)$ & $56.7(47-63.5)$ & .91 & 0.076 \\
\hline Gender (male), n (\%) & $34(38)$ & $29(32)$ & .44 & 0.116 \\
\hline Caucasian, n (\%) & $90(100)$ & $90(100)$ & 1.0 & 0.0 \\
\hline \multicolumn{5}{|l|}{ Comorbidities } \\
\hline Diabetes, $\mathrm{n}(\%)$ & $65(72)$ & $56(62)$ & .15 & 0.213 \\
\hline Hypertension, $\mathrm{n}(\%)$ & $78(87)$ & $71(79)$ & .17 & 0.205 \\
\hline Current tobacco use, $\mathrm{n}(\%)$ & $17(19)$ & $11(12)$ & .22 & 0.183 \\
\hline Prior vascular events, n (\%) & $21(23)$ & $16(18)$ & .36 & 0.137 \\
\hline Prior non-hepatic neoplasm, n (\%) & $14(16)$ & $17(19)$ & .55 & -0.087 \\
\hline BMI $\left(\mathrm{kg} / \mathrm{m}^{2}\right)$ & $35.03(30.5-41.1)$ & $35.8(32.3-41.7)$ & .31 & -0.183 \\
\hline \multicolumn{5}{|l|}{ Medication use } \\
\hline Metformin, $\mathrm{n}(\%)$ & $46(51)$ & $36(40)$ & .13 & 0.188 \\
\hline Sulfonylurea, n (\%) & $18(20)$ & $18(20)$ & 1.0 & 0.0 \\
\hline Insulin, $\mathrm{n}(\%)$ & $35(39)$ & $25(28)$ & .11 & 0.231 \\
\hline Pioglitazone, n (\%) & $10(11)$ & $2(2)$ & .02 & 0.360 \\
\hline Statin, n $(\%)$ & $41(46)$ & $29(32)$ & .07 & 0.274 \\
\hline SGLT2 inhibitor, $\mathrm{n}(\%)$ & $12(13)$ & $7(8)$ & .23 & 0.180 \\
\hline GLP-1 agonist, n (\%) & $4(4)$ & $1(1)$ & 0.17 & 0.202 \\
\hline \multicolumn{5}{|l|}{ Lab tests } \\
\hline $\operatorname{ALT}(\mathrm{U} / \mathrm{L})$ & $39(22-57)$ & $48(34-80)$ & $<.01$ & -0.423 \\
\hline $\operatorname{AST}(\mathrm{U} / \mathrm{L})$ & $43.5(31-62)$ & $55.5(38-73)$ & .01 & -0.394 \\
\hline INR & $1.1(1.03-1.18)$ & $1.08(1.02-1.15)$ & .29 & 0.143 \\
\hline Albumin (g/dl) & $3.9(3.6-4.2)$ & $3.95(3.7-4.3)$ & .42 & -0.103 \\
\hline Total bilirubin (mg/dl) & $0.75(0.5-1.1)$ & $0.7(0.5-1)$ & .37 & 0.119 \\
\hline Platelet count $\times 10^{9} / \mathrm{L}$ & $161(112-214)$ & $185(125-234)$ & .28 & -0.127 \\
\hline HbA1c (\%) & $6.4(5.2-8.9)$ & $6.3(5.4-7.8)$ & .61 & 0.105 \\
\hline Total cholesterol (mg/dl) & $162(127-193)$ & $172(144-199)$ & .17 & -0.146 \\
\hline HDL cholesterol (mg/dl) & $35(29-47)$ & $38(34-45)$ & .08 & -0.217 \\
\hline LDL cholesterol (mg/dl) & $86(63-115)$ & $99(76-124)$ & .06 & -0.277 \\
\hline Triglycerides $(\mathrm{mg} / \mathrm{dl})$ & $137(109-253)$ & $137(108-186)$ & .49 & 0.159 \\
\hline Creatinine (mg/dl) & $0.8(0.68-1)$ & $0.8(0.7-0.91)$ & .89 & 0.032 \\
\hline eGFR (CKD-EPI) $\mathrm{ml} / \mathrm{min} / 1.73 \mathrm{~m}^{2}$ & $88.9(71.5-102.6)$ & $87(73.7-101.3)$ & .93 & -0.024 \\
\hline CKD categories, $\mathrm{n}(\%)$ & & & .48 & 0.181 \\
\hline$\geq 90 \mathrm{ml} / \mathrm{min} / 1.73 \mathrm{~m}^{2}$ & $44(49)$ & $41(46)$ & & \\
\hline $60-89 \mathrm{ml} / \mathrm{min} / 1.73 \mathrm{~m}^{2}$ & $32(36)$ & $39(43)$ & & \\
\hline$<60 \mathrm{ml} / \mathrm{min} / 1.73 \mathrm{~m}^{2}$ & $14(16)$ & $10(11)$ & & \\
\hline Alfa-fetoprotein (ng/dl) & $3.4(2.7-4.1)$ & $3.4(2.8-4.3)$ & .96 & -0.101 \\
\hline \multicolumn{5}{|l|}{ Severity of liver disease } \\
\hline CTP score, n (\%) & & & .61 & -0.073 \\
\hline A5 & $82(91)$ & $80(89)$ & & \\
\hline A6 & $8(9)$ & $10(11)$ & & \\
\hline MELD score & $7.88(6.97-9.06)$ & $7.58(6.76-8.81)$ & .18 & 0.179 \\
\hline GEV, n (\%) & $34(38)$ & $29(32)$ & .44 & 0.116 \\
\hline Severity of fibrosis, n (\%) & & & .41 & 0.121 \\
\hline Bridging fibrosis & $24(27)$ & $29(32)$ & & \\
\hline
\end{tabular}

This article is protected by copyright. All rights reserved. 


\begin{tabular}{lllll}
\hline Cirrhosis & $66(73)$ & $61(68)$ & & \\
NAFLD activity score (NAS) & $4(3-5)$ & $4(3-5)$ & .21 & -0.189 \\
NAS $\geq 4, \mathrm{n}(\%)$ & $51(57)$ & $61(68)$ & .12 & -0.229 \\
Fib-4 index & $2.52(1.80-3.89)$ & $2.53(1.64-3.73)$ & .81 & 0.012 \\
Follow-up (years), $\mathrm{n}(\%)+$ & & & .77 & 0.027 \\
$\quad<4$ years & $19(21)$ & $22(24)$ & & \\
4-6 years & $30(33)$ & $26(29)$ & & \\
$\quad>6$ years & $41(46)$ & $42(47)$ & & - \\
Time on vitamin E, n (\%) & & & & - \\
2-4 years & - & $24(26)$ & & \\
4-6 years & - & $28(31)$ & & \\
$>6$ years & - & $48(53)$ & & \\
\hline
\end{tabular}

Abbreviations: BMI, body mass index; SGLT2, sodium-glucose cotransporter 2 inhibitor; GLP-1, glucagon-like peptide-1 receptor; ALT, alanine aminotransferase; AST, aspartate aminotransferase; INR, international normalized ratio; HbA1c, glycosylated hemoglobin; eGFR, estimated glomerular filtration rate; CKD, chronic kidney disease; CTP, Child-Turcotte-Pugh; MELD, model for end stage of liver disease; GEV, gastroesophageal varices; NAFLD, nonalcoholic alcoholic fatty liver disease; NAS, NAFLD activity score.

* McNemar's test for categorical variables and Wilcoxon sum-rank test for continuous variables.

$\uparrow$ The standardized differences approach was performed to compare mean and proportions of baseline features for assessment of covariate balance.(41)

$\$$ Follow-up in years after vitamin E was initiated.

Continuous variables are expressed as median and interquartile range.

This article is protected by copyright. All rights reserved. 
Table 2. Patient outcomes in vitamin E users and their propensity matched controls. Outcome distribution in the propensity-score matched groups.

\begin{tabular}{lll}
\hline & \multicolumn{2}{l}{ Propensity matched cohort, N=180 } \\
\cline { 2 - 3 } Outcomes & Controls & Vitamin E \\
& $\mathrm{n}=90$ & $\mathrm{n}=90$ \\
& $\mathrm{~N}(\%)$ & $\mathrm{N}(\%)$ \\
\hline All-cause mortality or transplant & $30(33)$ & $9(10)$ \\
Liver transplantation & $15(17)$ & $3(3.3)$ \\
Death & $15(17)$ & $6(7)$ \\
Non-liver related & $6(7)$ & $2(2.2)$ \\
Liver-related & $9(10)$ & $4(4.5)$ \\
Hepatic decompensation & $40(44)$ & $26(29)$ \\
Ascites & $20(22)$ & $10(11)$ \\
Variceal bleeding & $10(11)$ & $3(3)$ \\
Encephalopathy & $10(11)$ & $13(14.4)$ \\
HCC development & $7(8)$ & $5(6)$ \\
Major vascular event* & $10(11)$ & $7(8)$ \\
Cardiovascular & $10(11)$ & $5(5.5)$ \\
Ischemic stroke & $0(0)$ & $2(2.5)$ \\
Non-hepatic malignancy $\dagger$ & $3(3)$ & $3(3)$ \\
\hline Abbrevations: &
\end{tabular}

Abbreviations: HCC, hepatocellular carcinoma.

* A new episode of vascular disease including myocardial infarction, stable and unstable angina, impairment of heart failure, cardiac arrest, stroke, carotid or aortic artery disease, stroke, and transient ischemic attacks).

$\uparrow$ Vitamin E (colorectal cancer, 1; renal cell carcinoma, 1; duodenal carcinoid, 1). No vitamin E (lung cancer, 2; breast cancer, 1). 
Table 3. Vitamin E treatment effects on outcomes. Unadjusted and adjusted analysis in the propensity-score matched groups.

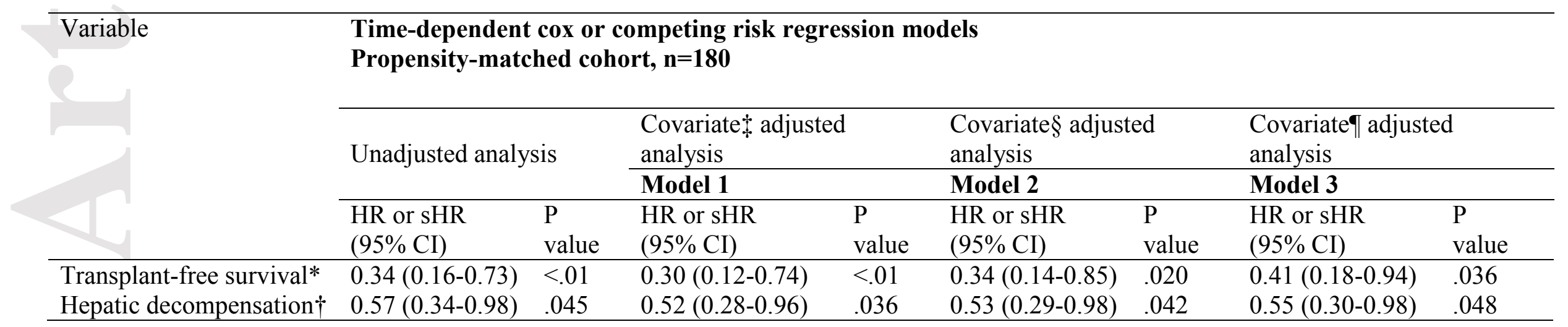

Abbreviations: HR, hazard ratio; sHR, subhazard ratio.

* Time-dependent cox regression models.

$\dagger$ Time-dependent competing risk regression models.

† Adjustments by age, gender, calendar year of patient enrollment, tobacco use, history of cardiovascular disease, BMI, hypertension, type 2 diabetes, fibrosis severity, presence of esophageal varices at baseline, LDL cholesterol and the use of antidiabetic medications, statins and aspirin.

$\S$ Adjustments by variables included in the model 1 plus MELD score.

- Adjustments by variables included in the model 1 plus total bilirubin, platelet count, albumin and INR.

This article is protected by copyright. All rights reserved. 
Table 4. Changes from baseline in selected baseline characteristics. Comparison between the two groups in the propensity-matched analysis.

\begin{tabular}{|c|c|c|c|c|c|c|c|}
\hline & Controls, $n=90$ & & & Vitamin $E, n=90$ & & & \\
\hline Variables & Baseline & $\begin{array}{l}\text { EOS, death or } \\
\text { transplant }\end{array}$ & $\begin{array}{l}\mathrm{P} \\
\text { value* }\end{array}$ & Baseline & $\begin{array}{l}\text { EOS, death or } \\
\text { transplant }\end{array}$ & $\begin{array}{l}\mathrm{P} \\
\text { value* }\end{array}$ & $\begin{array}{l}\text { P- value for } \\
\text { between- gro } \\
\text { up } \\
\text { comparison } \dagger\end{array}$ \\
\hline BMI $\left(\mathrm{kg} / \mathrm{m}^{2}\right)$ & $35.03(30.5-41.1)$ & $33.5(29.1-37.7)$ & .03 & $35.8(32.3-41.7)$ & $34.6(29-39.8)$ & .68 & .39 \\
\hline \multicolumn{8}{|l|}{ Lab tests } \\
\hline $\operatorname{ALT}(\mathrm{U} / \mathrm{L})$ & $39(22-57)$ & $28(18-42)$ & .03 & $48(34-80)$ & $29(19-37)$ & $<.01$ & $<.01$ \\
\hline AST (U/L) & $43.5(31-62)$ & $36(27-52)$ & .06 & $55.5(38-73)$ & $31(25-44)$ & $<.01$ & $<.01$ \\
\hline AST/ALT ratio & $1.28(0.91-1.61)$ & $1.36(1.02-1.75)$ & $<.01$ & $1.07(0.82-1.35)$ & $1.21(0.88-0.64)$ & $<.01$ & .96 \\
\hline INR & $1.1(1.03-1.18)$ & $1.22(1.08-1.62)$ & $<.01$ & $1.08(1.02-1.15)$ & $1.17(1.08-1.28)$ & $<.01$ & .01 \\
\hline$>1.7, \mathrm{n}(\%)$ & $0(0 \%)$ & $21(23 \%)$ & $<.01$ & $0(0 \%)$ & $6(7 \%)$ & .01 & $<.01$ \\
\hline Albumin $(\mathrm{g} / \mathrm{dl})$ & $3.9(3.6-4.2)$ & $3.6(2.8-4.1)$ & $<.01$ & $3.95(3.7-4.3)$ & $3.8(3.4-4.3)$ & $<.01$ & $<.01$ \\
\hline$<3.5, \mathrm{n}(\%)$ & $4(4 \%)$ & $45(50 \%)$ & $<.01$ & $10(11 \%)$ & $32(36 \%)$ & $<.01$ & .05 \\
\hline Total bilirubin (mg/dl) & $0.75(0.5-1.1)$ & $0.9(0.6-2.3)$ & $<.01$ & $0.7(0.5-1)$ & $0.85(0.6-1.2)$ & $<.01$ & .04 \\
\hline$>2.0, \mathrm{n}(\%)$ & $1(1 \%)$ & $32(36 \%)$ & $<.01$ & $0(0 \%)$ & $17(19 \%)$ & $<.01$ & .01 \\
\hline Platelet count $\times 10^{9} / \mathrm{L}$ & $161(112-214)$ & $123(79-205)$ & $<.01$ & $185(125-234)$ & $136(89-201)$ & $<.01$ & .40 \\
\hline HbA1c (\%) & $6.4(5.2-8.9)$ & $6.8(5.7-8.2)$ & $<.01$ & $6.3(5.4-7.8)$ & $6.6(5.6-8.05)$ & $<.01$ & .64 \\
\hline LDL cholesterol (mg/dl) & $86(63-115)$ & $77(61-112)$ & .42 & $99(76-124)$ & $76(55-102)$ & $<.01$ & .03 \\
\hline Triglycerides (mg/dl) & $137(109-253)$ & $132(95-211)$ & .65 & $137(108-186)$ & $116(78-163)$ & .17 & .77 \\
\hline Creatinine (mg/dl) & $0.8(0.68-1)$ & $0.84(0.73-1.22)$ & $<.01$ & $0.8(0.7-0.91)$ & $0.86(0.71-1.09)$ & .02 & .33 \\
\hline eGFR (CKD-EPI) $\mathrm{ml} / \mathrm{min} / 1.73 \mathrm{~m}^{2}$ & $88.9(71.5-102.6)$ & $79.5(58.5-99.9)$ & $<.01$ & $87(73.7-101.3)$ & $84.8(61.1-99.2)$ & $<.01$ & .39 \\
\hline CKD stages, n (\%) & & & $<.01$ & & & $<.01$ & .82 \\
\hline$\geq 90 \mathrm{ml} / \mathrm{min} / 1.73 \mathrm{~m}^{2}$ & $44(49)$ & $34(38)$ & & $41(46)$ & $38(42)$ & & \\
\hline $60-89 \mathrm{ml} / \mathrm{min} / 1.73 \mathrm{~m}^{2}$ & $32(36)$ & $33(37)$ & & $39(43)$ & $30(33)$ & & \\
\hline$<60 \mathrm{ml} / \mathrm{min} / 1.73 \mathrm{~m}^{2}$ & $14(16)$ & $23(26)$ & & $10(11)$ & $22(24)$ & & \\
\hline Fib-4 index & $2.52(1.80-3.89)$ & $3.16(1.55-6.04)$ & $<.01$ & $2.53(1.64-3.73)$ & $2.66(1.45-4.93)$ & .11 & .06 \\
\hline Fib-4 $>2.67$ & $42(47)$ & $53(59)$ & .019 & $43(48)$ & $45(50)$ & .83 & $<.01$ \\
\hline
\end{tabular}

This article is protected by copyright. All rights reserved. 
Abbreviations: BMI, body mass index; ALT, alanine aminotransferase; AST, aspartate aminotransferase; INR, international normalized ratio; HbA1c, glycosylated hemoglobin; eGFR, estimated glomerular filtration rate; CKD, chronic kidney disease.

* Wilcoxon signed- rank test or McNemar's test.

$\dagger$ Wilcoxon rank- sum test or Chi-square test.

Continuous variables are expressed as median and interquartile range.

This article is protected by copyright. All rights reserved. 


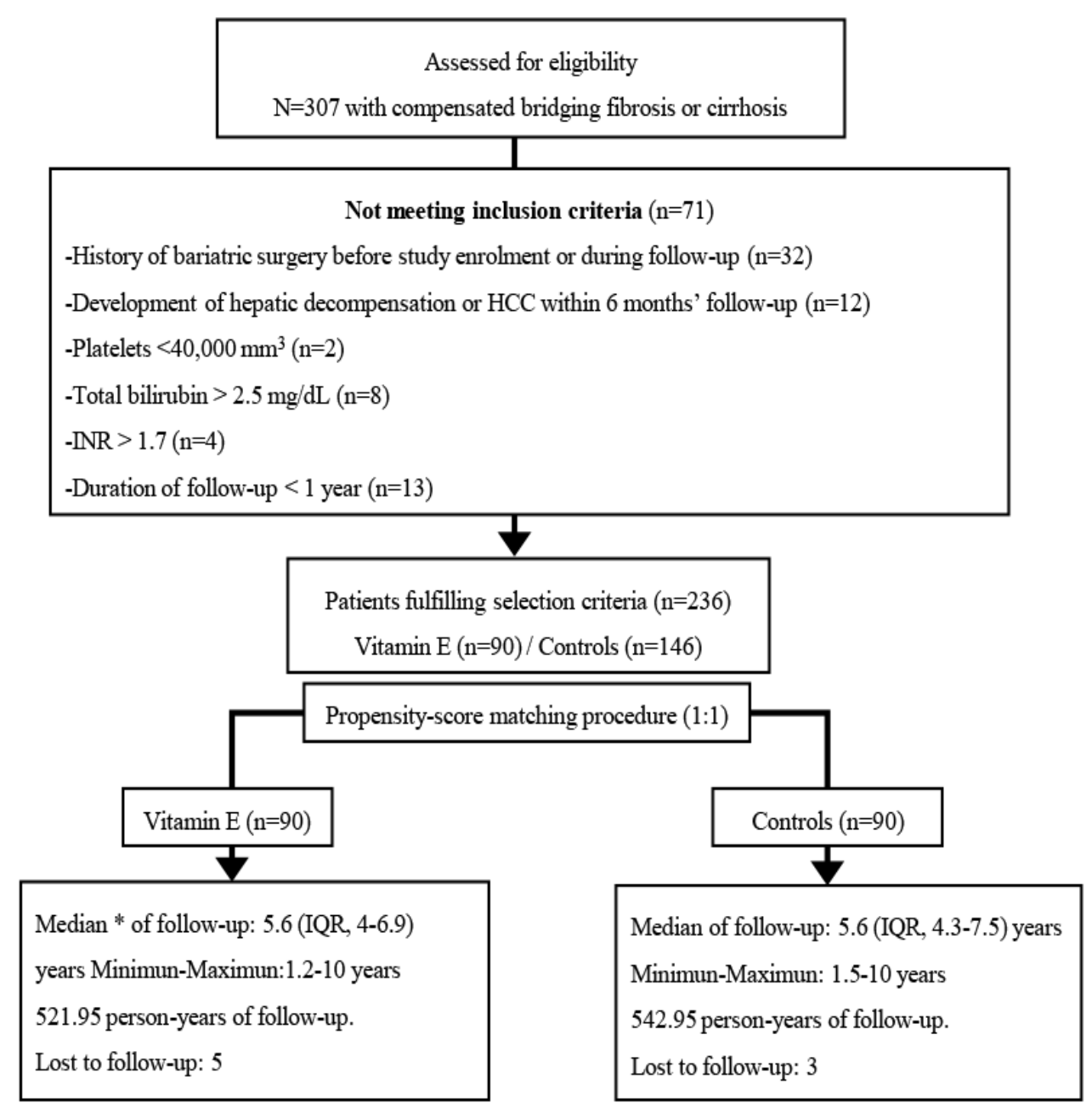

This article is protected by copyright. All rights reserved. 


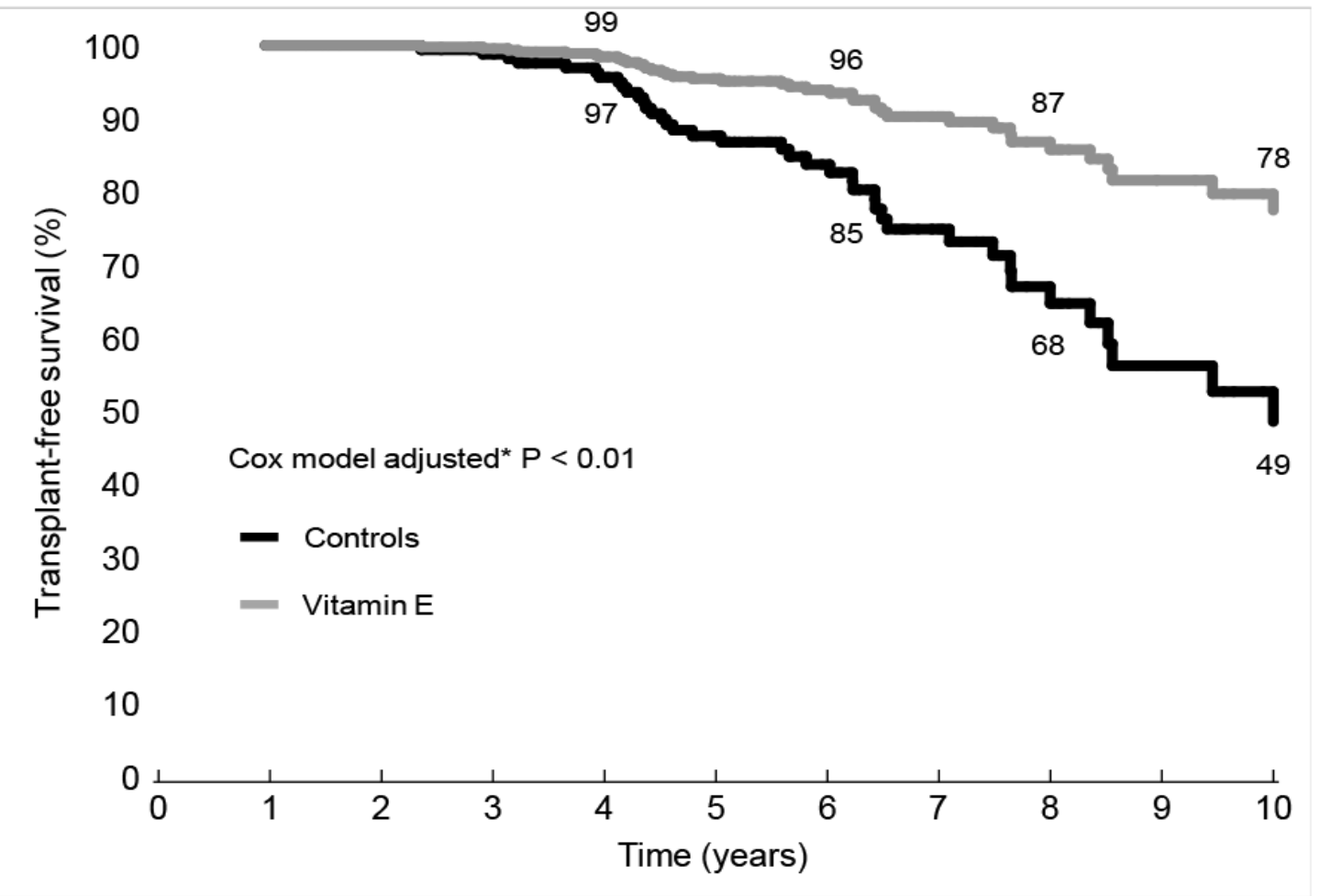

No. at risk

Vitamin E

90

$90 \quad 89 \quad 84$

$84 \quad 77$

Controls

$90 \quad 90 \quad 89$

$89 \quad 85$

$\begin{array}{lll}77 & 67 & 55\end{array}$

$\begin{array}{lllll}38 & 21 & 13 & 10 & 8 \\ 41 & 29 & 19 & 12 & 8\end{array}$

This article is protected by copyright. All rights reserved. 


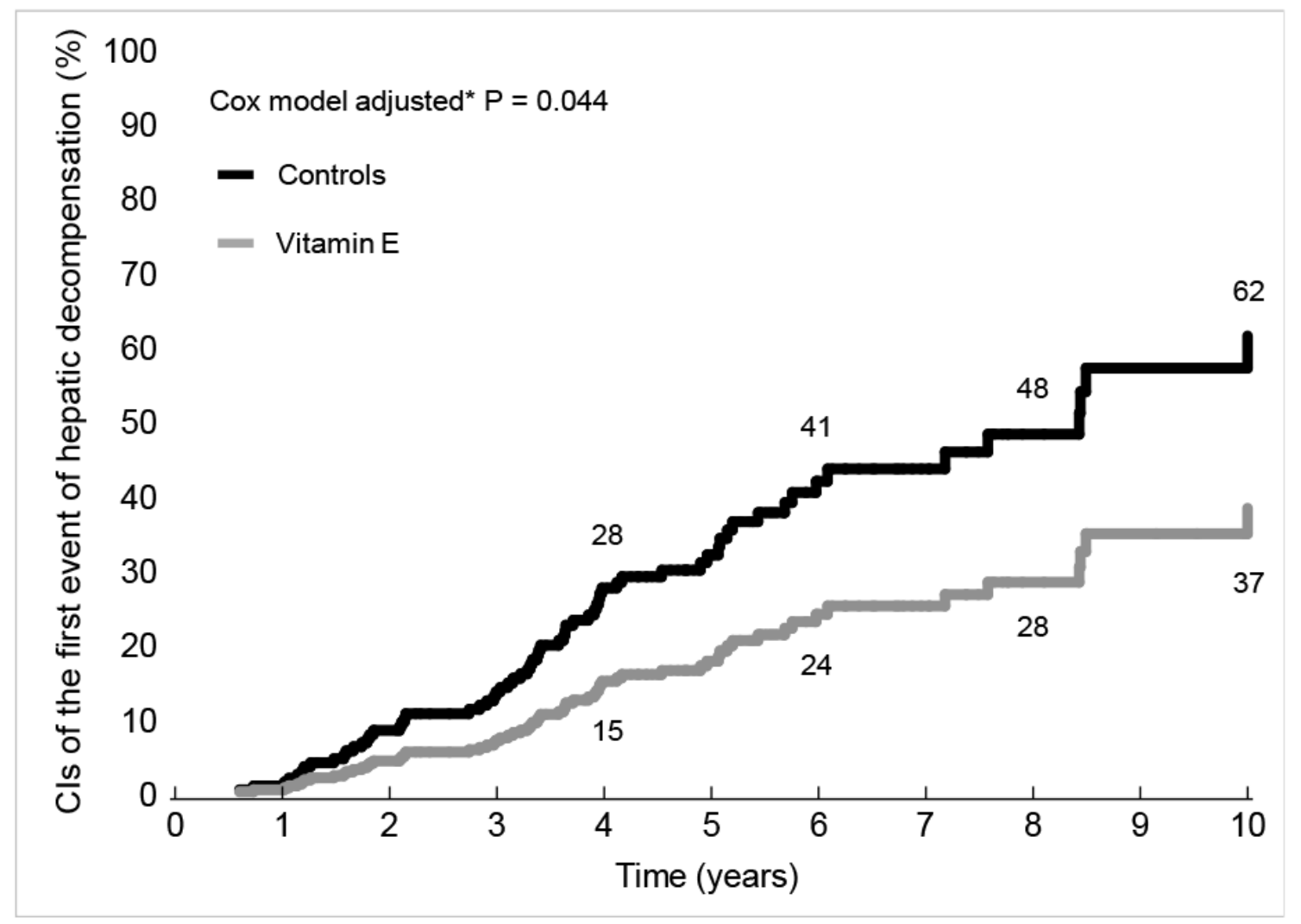

No. at risk

Vitamin E

Controls

$\begin{array}{lllllllllll}90 & 88 & 75 & 68 & 55 & 43 & 26 & 19 & 12 & 9 & 6 \\ 90 & 90 & 83 & 74 & 54 & 34 & 20 & 15 & 8 & 5 & 5\end{array}$

This article is protected by copyright. All rights reserved. 


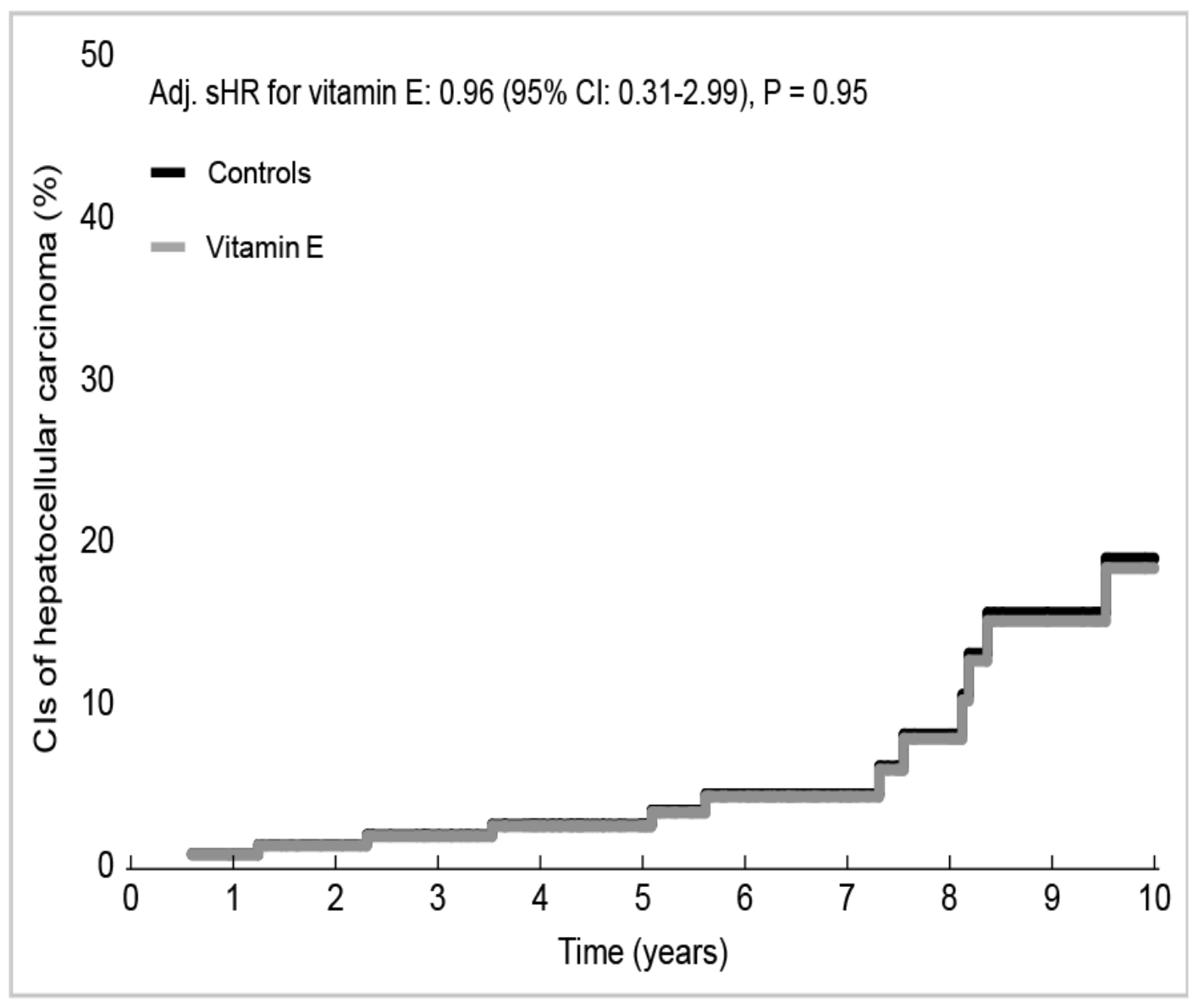

No. at risk

Vitamin E

Controls

$\begin{array}{ccccccccccc}90 & 88 & 82 & 75 & 66 & 54 & 36 & 20 & 13 & 9 & 7 \\ 90 & 90 & 89 & 84 & 75 & 55 & 41 & 29 & 19 & 11 & 7\end{array}$

This article is protected by copyright. All rights reserved. 


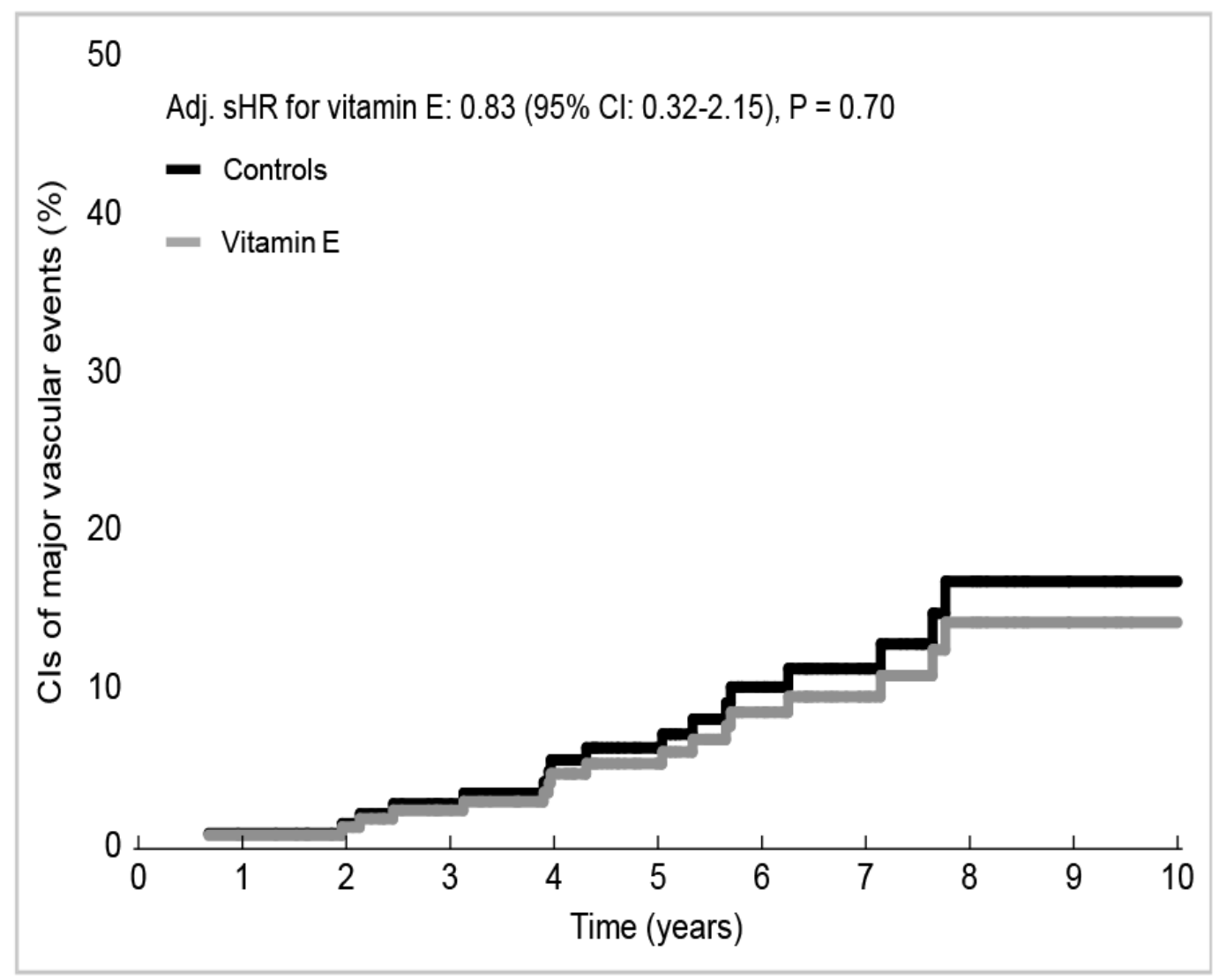

No. at risk

Vitamin E

Controls

$\begin{array}{lllllllllll}90 & 88 & 83 & 74 & 64 & 53 & 36 & 21 & 12 & 9 & 7 \\ 90 & 90 & 89 & 85 & 74 & 55 & 40 & 27 & 17 & 10 & 8\end{array}$

This article is protected by copyright. All rights reserved. 


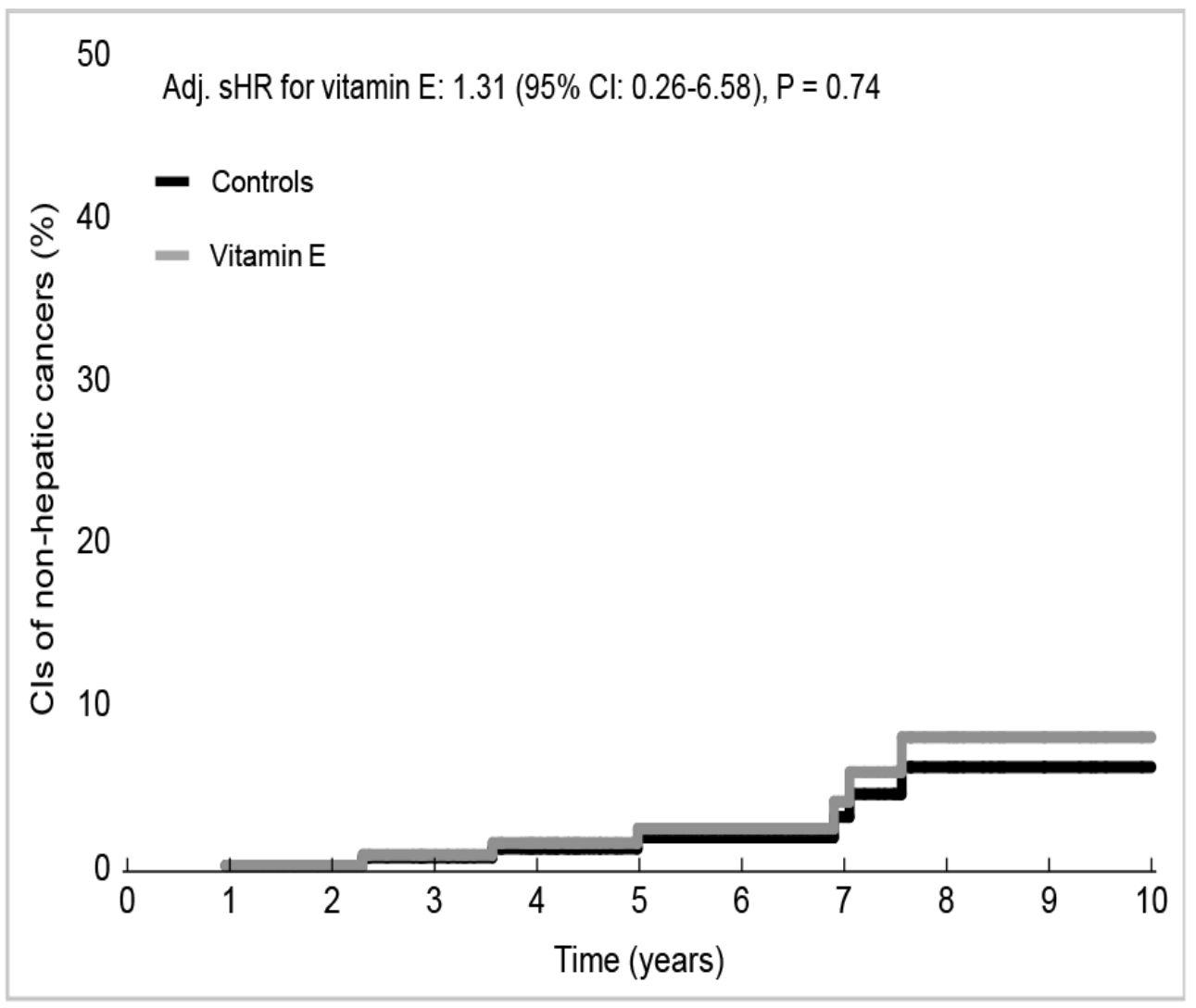

No. at risk

Vitamin E

Controls

$\begin{array}{lllllllllll}90 & 89 & 84 & 76 & 66 & 53 & 37 & 20 & 13 & 10 & 8 \\ 90 & 90 & 89 & 85 & 75 & 54 & 40 & 28 & 17 & 10 & 7\end{array}$

This article is protected by copyright. All rights reserved. 


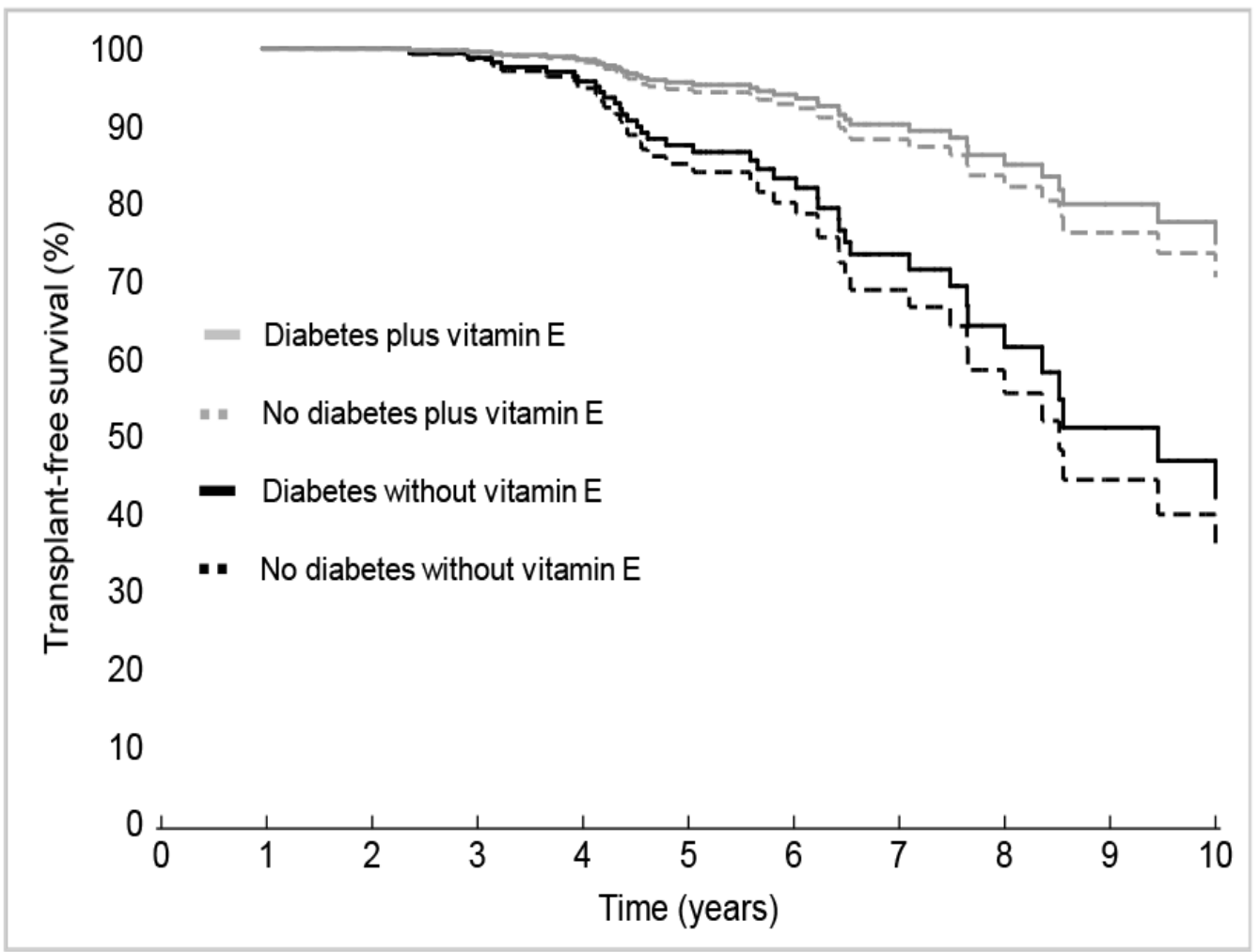

No. at risk

$\mathrm{T} 2 \mathrm{D}+\mathrm{vit} \mathrm{E}$

$T 2 D+$ no vit $E$

No $T 2 D+$ vit $E$

50

34

$65 \quad 64$

$\begin{array}{llllllll}62 & 57 & 42 & 29 & 20 & 14 & 10 & 6 \\ 28 & 24 & 21 & 15 & 11 & 7 & 5 & 5 \\ 23 & 19 & 13 & 12 & 9 & 5 & 2 & 2\end{array}$

This article is protected by copyright. All rights reserved. 